\title{
Hip fracture: the case for a funded national registry
}

\author{
Let's implement what we know and avoid deaths from hip fracture
}

Richard I Lindley MD, FRCP(Edin), FRACP Professor of Geriatric Medicine, ${ }^{l}$ and Honorary Professorial Fellow ${ }^{2}$

1 Sydney Medical School Westmead Hospital, Westmead Hospital,
University of Sydney, Sydney, NSW.

2 The George Institute for Global Health, Sydney, NSW.

richard.lindley@ sydney.edu.au
T he value of orthogeriatric care for hip fracture patients has been known for years, and a recent summary of international evidence has acknowledged the benefits. ${ }^{1}$ The NHS in England considered this so important that it offers serious financial incentives for hospitals to achieve an evidence-based standard of care - a "best-practice tariff" rewards hospitals that achieve the following key quality criteria:

- surgery within 36 hours

- shared care by surgeon and geriatrician

- care protocol agreed to by geriatrician, surgeon and anaesthetist

- assessment by geriatrician within 72 hours of admission

- preoperative and postoperative abbreviated mental test score assessment

- geriatrician-led multidisciplinary rehabilitation

- secondary prevention of falls

- bone health assessment. $^{2}$

This incentive, together with the United Kingdom's long established National Hip Fracture Database, has enabled monitoring of care and tracking of definite improvements. ${ }^{3}$ Hospitals are identified in the UK audit, so the poor performers cannot hide; this provides additional incentive to get things right.

Orthogeriatric care is not particularly complex. Like much of geriatric medicine, it is about doing a number of fairly simple things well. ${ }^{1}$ Geriatric assessment will help identify easily reversible problems before surgery (eg, electrolyte abnormalities, drug errors, fluid balance). Early surgery is safe and is the best way of relieving the severe pain of a hip fracture. The main driver of the bestpractice tariff - Keith Willett, Professor of Orthopaedic Trauma Surgery, University of Oxford - has said: "I don't believe the sun should set twice on a hip fracture" (personal communication). Early mobilisation with multidisciplinary care and good secondary prevention are key interventions after surgery.

In this issue of the Journal, Zeltzer and colleagues describe their investigation of the effects of orthogeriatric care in New South Wales. Their data suggest that there is unacceptable clinical variation. ${ }^{4}$ They found a statistically significant and clinically important difference in median adjusted 30-day mortality rate between 14 hospitals with an orthogeriatric service (6.2\%) and 23 without (8.4\%). Data from the Bureau of Health Information in NSW have also revealed important clinical variation between hospitals. ${ }^{5}$

While these data can tell us which hospitals have problems, only more detailed process data, such as data variables within a prospective clinical register, can help tell us why there is variation. Such data can then be used to implement change and improve care. Zeltzer et al suggest that the new Australian and New Zealand Hip Fracture Registry (http://www.anzhfr.org) will help improve hip fracture care. It is highly likely that if the Australian states and territories funded this register and made registration a requirement for activity-based funding that similar benefits to those seen in the UK could be achieved. This would contribute to a healthier old age. ${ }^{6}$ The stroke community, through the Australian Stroke Coalition (http://australianstrokecoalition.com.au), are moving in the same direction, as care for stroke patients has remarkable similarities to care for hip fracture patients: an acute intervention that needs timely administration (thrombolysis), organised multidisciplinary care (stroke units) and good secondary prevention.

If a rich country like Australia struggles to implement effective care, what hope is there for the Asia-Pacific region? The global health challenge is enormous, with over 400000 people dying from falls each year. ${ }^{7}$ Hip fracture rates in China are about to soar because of demographic change. The number of people aged over 80 years in China will increase from the current 8 million to some 100 million by $2050 .^{8}$ It will be a medical disaster for low- and middle-income countries to adopt some aspects of hip fracture care (expensive prostheses and surgery) without the other essentials (orthogeriatric care). The global challenge is to find the right incentives, training, health care services and funding to implement affordable effective health care. Orthogeriatric care in these countries is not an impossible dream as these services depend on people, rather than expensive technology.

I recommend that the managers and clinicians in those 23 NSW hospitals without orthogeriatric services now reorganise their services so the next 5000 patients with hip fracture who arrive at their emergency departments in the next 2 years receive a higher standard of care, have a lower risk of dying, and have a higher chance of better quality of life.

The key challenge of 21st century medicine is finding and implementing affordable health care, not only in low-and middle-income countries but also in Australia. 


\section{Competing interests: No relevant disclosures.}

Provenance: Commissioned; externally peer reviewed.

1 National Clinical Guideline Centre. The management of hip fracture in adults. London: NCGC, 2011. http://www.nice.org.uk/guidance/cgl24/ resources/cgl24-hip-fracture-full-guideline (accessed Aug 2014).

2 Department of Health Payment by Results Team. Payment by results guidance for 2013-14. Leeds: Department of Health, 2013. https://www.gov. uk/government/uploads/system/uploads/attachment_data/file/214902/ PbR-Guidance-2013-14.pdf (accessed Aug 2014).

3 National Hip Fracture Database. National report 2013. London: Clinical Effectiveness and Evaluation Unit, Royal College of Physicians, 2013. http:// www.nhfd.co.uk/20/hipfractureR.nsf/welcome?readform (accessed Aug 2014)
4 Zeltzer J, Mitchell RJ, Toson B, et al. Orthogeriatric services associated with lower 30-day mortality for older patients who undergo surgery for hip fracture. Med J Aust 2014; 201: 409-411.

5 Bureau of Health Information. The insights series: 30-day mortality following hospitalisation, five clinical conditions, NSW, July 2009 - June 2012. Sydney: BHI, 2013. http://www.bhi.nsw.gov.au/_data/assets/pdf file/0018/204309/30-day-Mortality_December2013.pdf (accessed Aug 2014).

6 Close JC. Hip fracture in Australia: missed opportunities and a chance to improve care. Intern Med J 2013; 43: 1262-1264.

7 Jagnoor J, Keay L, Ivers R. A slip and a trip? Falls in older people in Asia. Injury 2013; 44: 701-702.

8 World Health Organization. Good health adds life to years. Global brief for World Health Day 2012. Geneva: WHO, 2012. http://www.who.int/ageing/ publications/whd2012_global_brief/en (accessed Aug 2014). 
for mental health problems. This perception may have arisen from the inclusion of questions designed to elicit parent concerns about the child's behaviour, and because funding for the development of the EHKC was provided by the mental health branch of the Department of Health. Rather than being a screening test, the EHKC was conceptualised as providing an opportunity for parents to raise any concerns with their child's GP. These would be addressed using the GP's clinical judgement - reassurance, providing appropriate advice, or referral for further assessment and management — facilitated by appropriate training and a mapping template to document local community supports and referral agencies. The government is apparently considering the evaluation report, generally very positive, but no decision has been made about the introduction of the EHKC. Meanwhile, the HKC continues as a Medicare-funded check for 4-year-olds.

While the idea of prevention and intervention early in life is compelling and the research underpinning it largely uncontested, it is a hard sell to government and there are many challenges in its implementation. Early detection of emerging problems is problematic. Many issues in young children are transient, and we do not have reliable and valid methods to know which children we should be concerned about. The evidence suggests that systematically eliciting and responding to parent concerns is the best method for early detection (Murdoch Childrens Research Institute, Centre for Community

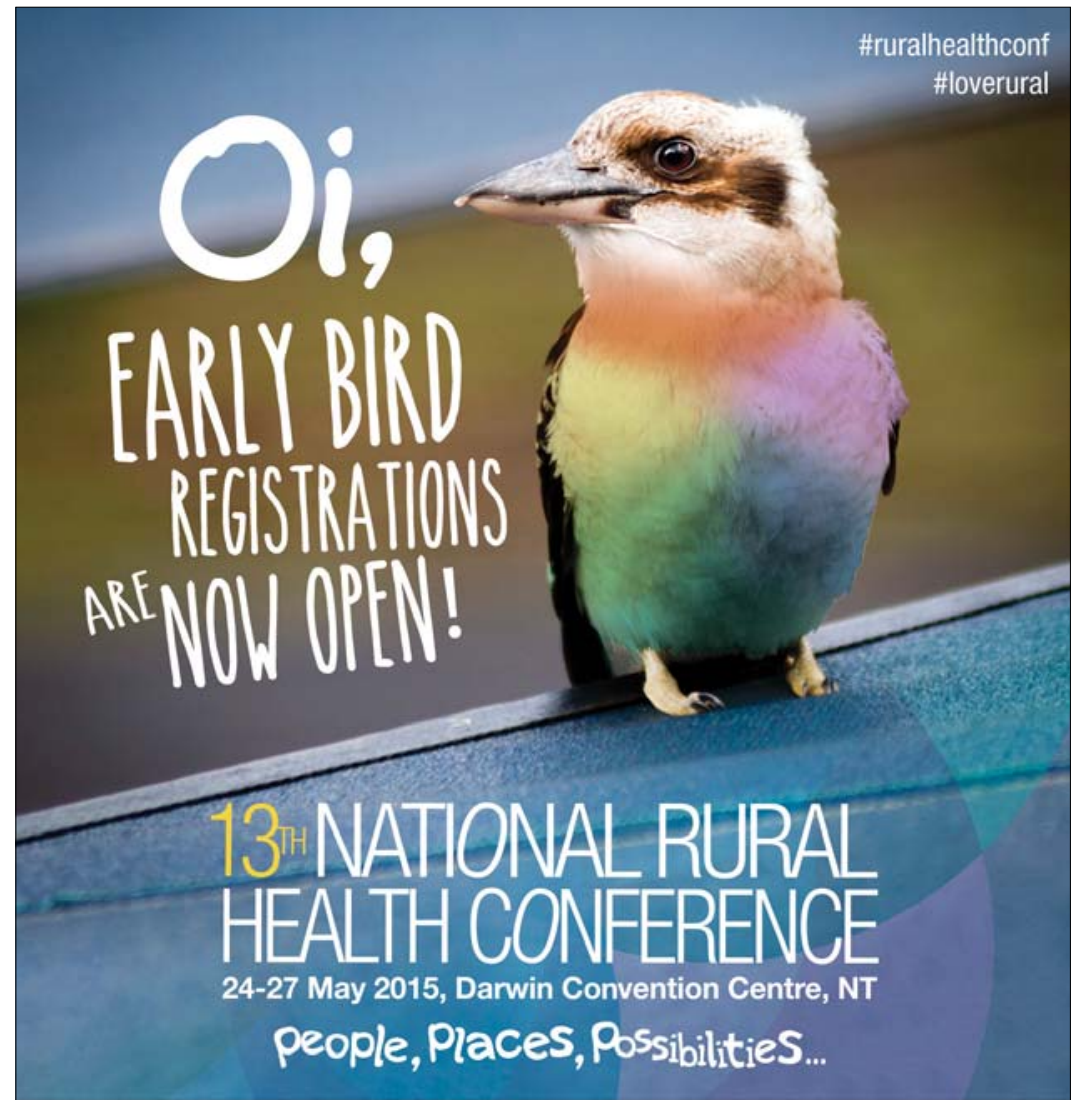

Register online at www.ruralhealth.org.au/conference
Child Health; submission to the Victorian Government, March 2009). Making the check part of Medicare removes a potential financial barrier for uptake but still does not ensure that all children, especially those at risk, are seen in a timely fashion.

The primary health care system must be at the heart of efforts to refocus the health system towards prevention and early intervention, so GP involvement in undertaking the child health checks is important. It is to be hoped that the government persists with the ongoing review and informed evolution of the child health check, and that the challenges and concerns that are an inevitable accompaniment to introducing any population health measure are addressed appropriately.

Competing interests: I chaired the expert working group that made recommendations to the government about the EHKC.

Provenance: Commissioned; externally peer reviewed.

1 Duncan GJ, Kalil A, Ziol-Guest KM. Early childhood poverty and adult achievement, employment and health. Family Matters 2013; 93: 27-35.

2 Oberklaid F, Wake M, Harris C, et al. Child health screening and surveillance: a critical review of the evidence. Canberra: National Health and Medical Research Council, 2002

3 Alexander KE, Mazza D. The Healthy Kids Check - is it evidence based? Med J Aust 2010; 192: 207-210.

4 Thomas R, Doust JA, Vasan K, et al. Identified health concerns and changes in management resulting from the Healthy Kids Check in two Queensland practices. Med J Aust 2014; 201: 404-408.

5 Daubney MF, Cameron CM, Scuffham PA. Changes to the Healthy Kids Check: will we get it right? Med J Aust 2013; 198: 475-477.

6 Prior M. Why screening and treating 3-year-olds for mental health problems is not such a good idea. Aust N Z J Psychiatry 2012; 46: 700-710.

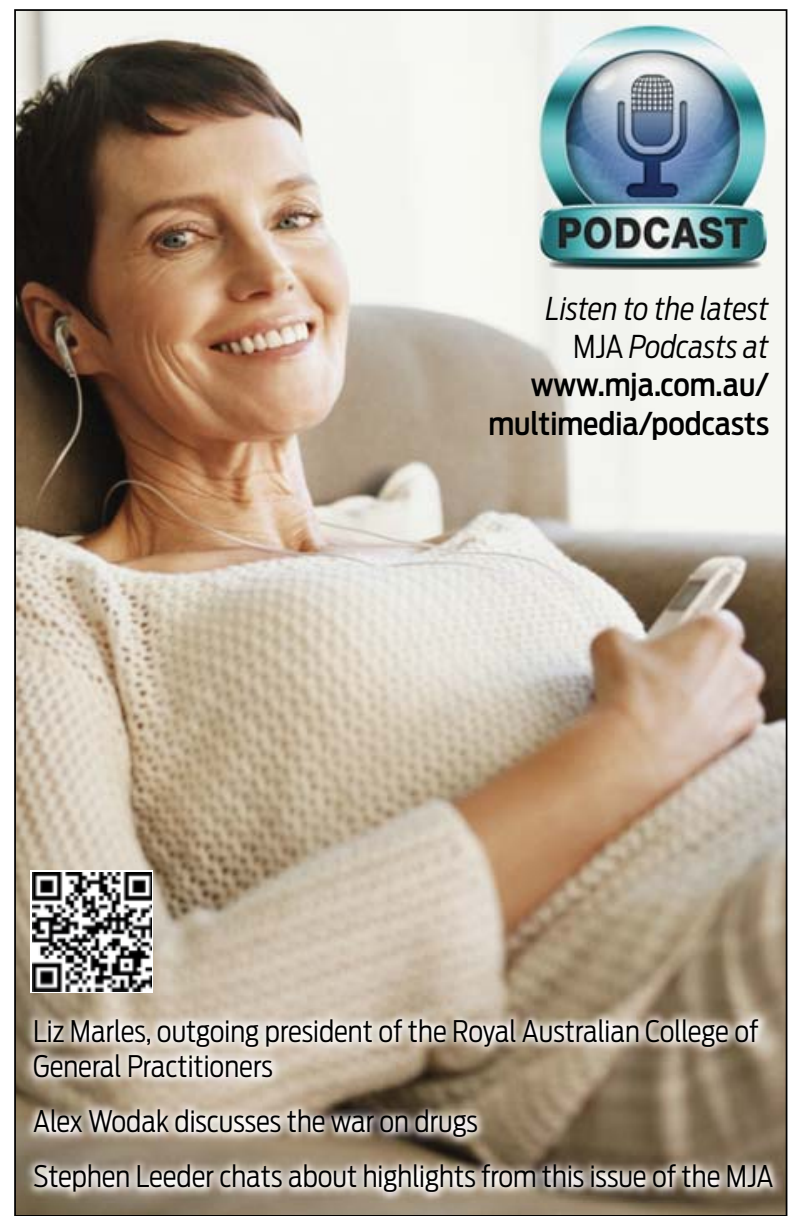

